\title{
A REVELAÇÃO DO ABUSO SEXUAL INTRAFAMILIAR INFANTIL: PROTEÇÃO DA VÍTIMA E RESPONSABILIZAÇÃO DO AGRESSOR
}

\section{THE REVELATION OF CHILD'S INTRAFAMILY SEXUAL ABUSE: PROTECTING THE VICTIM AND RESPONSIBILITY OF THE AGGRESSOR}

\author{
Rafaella de Oliveira Moura * \\ Nabiha de Oliveira Maksoud ${ }^{* \star}$ \\ Heitor Romero Marques ${ }^{* \star *}$
}

Resumo: O presente artigo versa sobre a revelação do abuso sexual infantil quando ocorre no ambiente familiar. O estudo contempla a função social do direito e interculturalidade como linha de pesquisa, apresentando como subárea direitos sociais e políticas públicas, tendo como base a pesquisa bibliográfica, de abordagem diagnóstica. A proposta consiste em encorajar a revelação do abuso pela criança e nos procedimentos a serem adotados após essa identificação. Os resultados evidenciam que a subnotificação desses casos relaciona-se a diversos fatores de ordem subjetiva, que são engendrados pelo agressor como garantia da sua impunidade, por isso a necessidade de transformação dessa condição velada em que se estabelece a violência, com o reconhecimento dos sinais manifestados pelas crianças abusadas e implementação obrigatória da disciplina de educação sexual nas escolas da rede pública e privada, como conscientização da vítima para sua defesa e empoderamento na revelação, com a posterior denúncia na esfera processual penal.

Palavras-Chave: Abuso Sexual Infantil. Subnotificação no Ambiente Familiar. Identificação dos Sinais Manifestos. Educação Sexual nas Escolas. Responsabilização Penal do Agressor.

Abstract: This article deals with the disclosure of child sexual abuse when it occurs in the family environment. The study considers the social function of law and interculturality as a line of research, presenting social rights and public policies as a sub-area, based on bibliographic research, of a diagnostic approach. The proposal is to encourage the disclosure of abuse by the child and the procedures to be adopted after this identification. The results show that the underreporting of these cases is related to several subjective factors, which are engendered by the aggressor as a guarantee of his or her impunity, therefore there is the need to transform this veiled condition in which violence is established, with the recognition of the signs manifested by abused children and the mandatory implementation of the discipline of sexual education in public and private schools, as awareness of the victim for his or her defense and empowerment in the disclosure, with the subsequent denunciation in the criminal procedure sphere.

\footnotetext{
*Bacharel em Direito. E-mail: rafaellamoura4@gmail.com

** Advogada. Especialista em Direito Público do Estado e das Relações Sociais. Mestre em Psicologia da Saúde. E-mail: namaksoud@hotmail.com

${ }^{* \star \star}$ Especialista em Administração Rural pela Universidade Federal de Lavras, mestre em agronegócios pela Universidade Federal de Mato Grosso do Sul. Doutor em Medicina Veterinária Preventiva pela Unesp / Jaboticabal. Professor da Universidade Católica Dom Bosco nos cursos de Medicina Veterinária e Zootecnia. E-mail: heiroma@ucdb.br
} 
Keywords: Child Sexual Abuse. Underreporting in the Family Environment. Identification of Manifest Signs. Sex Education in Schools. Criminal Accountability of the Aggressor.

Recebido em: 13/09/2020.

Aceito em: 18/11/2020. 


\section{CONSIDERAÇÕES INICIAIS}

A infância, de modo genuíno, remete à pureza, inocência, felicidade, sonhos, transformações e esperança na edificação de um mundo melhor. Desde o princípio, a criança depende do ambiente a sua volta para sua sobrevivência. A relação de dependência que se estabelece com base nisso é determinante para seu desenvolvimento, por isso a extrema importância na consistência dos vínculos primários para seu crescimento e autonomia. Contudo, a violência sexual na família representa uma transgressão a esse direito de convivência familiar protetora por essas pessoas em processo de desenvolvimento físico, psicológico, moral e sexual, pois impede a formação de sua autonomia, que fica subordinada à vontade do agressor.

A violência sexual, um fenômeno multicausal e muito antigo, que atinge sem distinção, todos os estratos sociais, deve ser analisado de forma sistêmica, e não como um ato isolado. A violência é compreendida por um sistema de relações formado historicamente por princípios, regras e ideologias que estão necessariamente interligadas em uma sociedade, representando uma violação da responsabilidade de amparo e cuidado dos responsáveis, e consequentemente, uma coisificação da infância, ou seja, uma discordância de que as crianças devem ser tratadas como sujeitos de direitos.

A violência sexual pode ser assimilada com base em duas especificidades: exploração sexual e abuso sexual - sendo este último o objeto de interesse do presente artigo. Considerando que a criança ainda não possui independência emocional e maturidade plena para entender e consentir atos sexuais, presume-se que sua participação ocorre por meio de coerção física ou psicológica, infringindo os tabus sociais e papéis familiares. As espécies de atos são diversas, incluindo atividades sem contato físico, como o exibicionismo, as conversas obscenas, o voyeurismo, a exibição de material pornográfico; e com contato físico, abrangendo distintos estágios de intimidade que vão de beijos, carícias nos órgãos sexuais, masturbação, até penetração oral, anal ou genital, com pênis ou objetos, de forma forçada.

O abuso sexual infantil no ambiente familiar está vinculado com a condição de autoridade que o abusador exerce sobre a vítima, que utiliza dessa relação de poder para que, sem o consentimento válido da vítima, inicie sutilmente sua 
manipulação, à medida que os contatos sexualizados tornam-se cada vez mais íntimos. Dessa forma, em grande parte das situações, essa relação abusiva é mantida em sigilo por um longo período de tempo, sem a notificação e a consequente denúncia por parte da vítima, podendo ultrapassar gerações, impossibilitando assim a procura de ajuda.

Diante desse contexto, este trabalho tem como objetivo mostrar a importância da integração da família, da sociedade e do Estado na criação de ambientes seguros e acolhedores que incentivem a revelação do abuso sexual por parte das crianças, apresentando subsídios para que eles possam dar uma assistência digna no caso de identificarem ocorrências de violência sexual, com a indicação de como deve ser feito o procedimento para o encaminhamento das vítimas aos órgãos de proteção, para que, por meio da denúncia na esfera processual penal, possa haver a responsabilização do agressor, com a anulação do sentimento de culpa existente na criança e resgate de sua segurança, quebrando assim o ciclo de violência dentro das famílias.

O estudo, que tem como linha de pesquisa a função social do direito e a interculturalidade, apresentando como subárea os direitos sociais e políticas públicas, possui relevância social por estimular um olhar atento e cuidadoso por parte de toda a sociedade perante essas vítimas fragilizadas que carecem de apoio dentro do próprio lar, possibilitando o reconhecimento de indícios manifestos pelas crianças, com a procura de ajuda para um tratamento especializado, objetivando a superação do trauma vivenciado. Há relevância jurídica por incentivar a realização do relato da vítima, com posterior denúncia aos órgãos de proteção, a fim de reforçar a verdade na sua palavra e reconhecer sua condição de vítima pelo sistema judicial, com a condução do abusador a assumir a responsabilidade pelo o que foi feito, contribuindo assim para a construção da justiça social.

A pesquisa se classifica em exploratória devido ao envolvimento investigativo em literatura a fim de que se pudesse aprofundar as buscas e familiarizar-se com o tema. Com a finalidade de constatar uma limitação para uma busca dentro de um contexto literário, o levantamento bibliográfico teve como base livros, revistas, artigos científicos e documentos monográficos, além de sites e vídeos envolvendo o conteúdo analisado sob fundamentação dos Direitos Humanos. E, ainda, análise da legislação vigente e de doutrinas acerca do tema. 
Devido aos fins para ampliar a área de conhecimento do Direito Processual Penal e dos Direitos Humanos, essa pesquisa se enquadra na natureza básica e contempla a abordagem diagnóstica, devido ao método de análise hipotético-dedutivo que gira em torno de uma hipótese e problema que serão analisados com base dentre outros, nos autores Lygia Maria Pereira da Silva, Elaine Christovam de Azevedo e Benedito Rodrigues dos Santos, representando fontes secundárias de pesquisa, publicadas no período de 1983 a 2020.

De início, foi elaborado o estado da questão a partir de levantamento bibliográfico, registrando-se como se encontrava o tema objeto de investigação no estado atual da ciência ao seu alcance, delimitando o problema específico da pesquisa. Em seguida, foi organizado um esboço com perspectivas quanto ao tema, estabelecendo os tópicos com conteúdos específicos escolhidos por meio da identificação da subnotificação do abuso sexual infantil, mais especificamente dentro do ambiente familiar. Por fim, sucedeu à formulação de perguntas analíticas que conduziu à elaboração de hipóteses para a questão a ser respondida no desenvolvimento deste artigo.

\section{BREVE HISTÓRICO}

No transcorrer da história da humanidade, a negligência contra crianças foi um marco importante na formação da cultural pois não existia a noção de vulnerabilidade inerente à infância, pouco se tratava acerca da questão e, por conseguinte, não havia uma política de proteção. Azambuja (2004, p. 21) revela que a prática de violência contra crianças era habitual na Antiguidade, pela existência de quantidade significativa de registros bíblicos e mitológicos referentes à relação injusta e desproporcional do adulto em relação à criança, conforme narrado pelo autor na seguinte passagem:

Caim matou Abel, enquanto Zeus sequestrou o jovem Ganimedes para the servir de copeiro e amante. O livro A Vida dos Doze Césares, de Suetônio, registrou as inclinações sexuais do imperador romano Tibério com crianças: ele se retirou para a ilha de Capri com várias crianças pequenas, as quais forçava a cometerem atos sexuais vulgares e a atenderem a seus desejos $[\ldots]$.

Desde o princípio os pais abusavam do poder disciplinador e coercitivo deixando marcas irreparáveis nas existências de suas crianças. Por um período muito 
longo, a violência praticada contra esse segmento foi justificada como medida disciplinar, estabelecida sem nenhuma sanção, uma vez que nesta relação o pai tinha poderes de vida e morte sobre seus filhos. Consoante o psico-historiador Lloyd de Mause (1975):

\begin{abstract}
A história da infância é um pesadelo do qual, recentemente começamos a despertar. Quanto mais atrás regressamos na história mais reduzido o nível de cuidado com as crianças, maior a probabilidade de que houvessem sido assassinadas, espancadas, aterrorizadas e abusadas sexualmente (MAUSE apud GUERRA, 2011, p.53).
\end{abstract}

No Brasil, a negligência, a opressão e a violência infantil acontecem desde a Sociedade Colonial, perpassando a Sociedade Imperial, o Brasil República, até os dias atuais. Em nossa sociedade, o primeiro trabalho científico publicado por professores da Faculdade de Ciências Médicas da Santa Casa de São Paulo sobre o tema foi a descrição do "Caso Araceli", uma menina de apenas oito anos que foi raptada, drogada, estuprada, morta e carbonizada, em 18 de maio de 1973, no Espírito Santo, e o julgamento teve a absolvição dos acusados e foi arquivado pela Justiça, tal fato instituiu o Dia Nacional de Combate ao Abuso e à Exploração Sexual de Crianças e Adolescentes pela Lei no 9.970/2000.

Ao longo da década de 1980 publicou-se o primeiro livro brasileiro sobre o tema: "Violência de pais contra filhos: procuram-se vítimas", de autoria da Dra . Viviane Nogueira de Azevedo Guerra (de 1998). Além desta, a Drā- Maria Amélia Azevedo também se dedicou a compreender a dinâmica das relações familiares e propor uma teoria explicativa para o fenômeno da violência com a criação do Laboratório de Estudos da Criança (LACRI) em "conjunto com o curso de formação de especialistas à distância, que construiu um conhecimento científico sobre a violência doméstica contra crianças, tornando-se referência no país" (SILVA, 2002, p.29).

Foi somente a partir dos anos 1980 que se passou a perceber, realmente, uma modificação na forma de lidar com a infância no Brasil. O Código de Menores, consolidado em 1927 pelo então Presidente da República Washington Luiz Pereira de Souza, por meio do Decreto n 17.943-A, que tinha o objetivo de dar assistência e proteção aos menores, principalmente àqueles que estivessem em situação de abandono ou delinquência, foi considerado ineficaz pela abertura democrática do momento político, e levou à busca de uma abordagem inovadora. Azambuja (2005) descreve que começou a ocorrer enorme interesse em relação a essa temática, com 
o aumento de pesquisas, seminários e cursos que resultaram no I Seminário LatinoAmericano de Alternativas Comunitárias de Atendimento a Meninos e Meninas de Rua, em 1984, um marco na luta pelos direitos das crianças e adolescentes.

Ainda na década de 1980, foram criados os primeiros serviços de atendimento com o objetivo de denunciar e encaminhar os casos de violência praticada por pais ou responsáveis contra seus filhos. Assim, em 1985, foi fundado em Campinas, o "Centro Regional de Atenção aos Maus-tratos na Infância (CRAMI), realizando um trabalho de recebimento de denúncias e encaminhamentos médicos e legais de toda a sociedade" (SILVA, 2002, p. 29-30). E, em 1988, ainda em São Paulo, a Ordem dos Advogados do Brasil (OAB) em conjunto com as Secretarias de Justiça e do Menor, além da Procuradoria Geral do Estado de São Paulo, alicerçados à Rede Criança, criaram o Serviço de Advocacia da Criança (SAC), a fim de lutar contra a violência à criança, de maneira sistemática.

No início da década de 1990 estabeleceu-se uma articulação do Poder Público Federal com a sociedade civil, transformando em preceito constitucional as concepções da Convenção Internacional dos Direitos da Criança. Todo esse processo acabou levando à aprovação da Lei no 8069 - o Estatuto da Criança e do Adolescente (ECA) - uma legislação inovadora que substituiu o já ultrapassado Código de Menores. O ECA enxergou a criança como cidadã e ser em desenvolvimento, passíveis de direitos e merecedores de proteção integral (BRASIL, 1990).

A evolução da legislação deu origem a diversas transformações que vão além da área jurídica e se desenvolvem em outros campos da realidade política e social. $A$ nova era dos direitos da infância, denominada Doutrina da Proteção Integral, motivou alterações na abordagem em relação às garantias jurídicas desses sujeitos, contudo, os índices de violência contra essa parcela da sociedade pressupõem que ainda há muito o que progredir.

\section{A SUBNOTIFICAÇÃO DO ABUSO SEXUAL INFANTIL NO AMBIENTE FAMILIAR}

No Brasil, as estatísticas da violência sexual contra crianças estão longe de espelhar a realidade atual, em face da subnotificação dos casos. De acordo com a Secretaria de Estado de Justiça e Segurança Pública (SEJUSP), o Disque 100, serviço de proteção a crianças e adolescentes com foco em violência sexual, recebe cerca de 50 notificações por dia com narrativas de crimes sexuais cometidos contra 
menores em todo Brasil, e cerca de $80 \%$ desta totalidade são notificações de abuso sexual. Entretanto, este número de casos que chega às autoridades policiais representa apenas 10\% do que efetivamente acontece na realidade (OBANDO, 2020).

O receio em revelar as experiências de vitimização pode estar relacionado ao medo das possíveis ameaças por parte do agressor, à insegurança da possível desconfiança de seu relato, afirmando-se que fantasiou ou inventou a experiência; medo da acusação de ser responsabilizado por ter seduzido o agressor; ao temor de ser o causador da dissolução familiar; ao receio de seu trauma ser minimizado pela alegação de que não houve nenhum dano e que é preferível esquecer o assunto, ou, ainda, a não revelação pode estar atrelada à falta de informação e consciência acerca do que é abuso sexual (AZEVEDO, 2001).

O emprego de manobras intimidatórias pelos agressores advém da busca pela preservação do silêncio das vítimas, impedindo o rompimento desmoralizado da homeostase do sistema familiar. A subnotificação dos índices de abuso sexual contra crianças representa um atraso no combate ao crime, pois é por meio do levantamento de dados estatísticos que os governantes idealizam as medidas públicas preventivas. A instauração de uma realidade desconhecida caracteriza mais um modo de violência que atua no âmbito estrutural da invisibilidade, acompanhada pelo descaso e indiferença.

\section{A RELAÇÃO ENTRE O SILÊNCIO DA VÍTIMA E A IMPUNIDADE DO AGRESSOR}

O abuso sexual intrafamiliar também está relacionado à questão da lealdade e confiança que a criança deposita no agressor, que se aproveita dessa relação para obter o seu silêncio. As particularidades dessa espécie de crime contribuem de forma expressiva para a manutenção da impunidade do agente. Uma grande dificuldade a ser enfrentada pela Justiça é de que nesses casos, o agressor é uma pessoa próxima da vítima, comumente pais, mães, tios, avós e irmãos. De acordo com o Boletim Epidemiológico do Ministério da Saúde, 69,2\% da violência sexual contra vulneráveis acontece no ambiente familiar (BRASIL, 2018), esse vínculo contribui para que os dados sejam ocultos, pois aquele que agride é quem a criança mais confia, ama e deve obediência.

O agressor não pode ser entendido pela pobreza, patologia ou descontrole. O estereótipo preconcebido do abusador pela sociedade não condiz com a realidade 
fática, já que esse agente, na maioria das vezes, trata-se de um cidadão de aparência comum, geralmente muito querido pela vítima, o que facilita o seu acesso a ela e à prática delituosa, contribuindo assim para o caráter subdimensionado dos casos (CORRÊA, 2009). A violência intrafamiliar é essencialmente democrática em sua disseminação, não há distinção de credo, etnia, raça ou classe social.

É necessário superar o mito de que o abusador sexual infantil é sempre um psicopata, um depravado sexual, um tarado que todos reconhecem na rua, um alcoólatra ou drogado. Na maioria dos casos trata-se de uma pessoa comum, que busca manter resguardados os demais âmbitos de sua personalidade, ou seja, é alguém que pode ter uma profissão e ser brilhante em sua atuação, pode ter uma família sendo repressor e moralista, pode ter um intelecto sensato e perspicaz, sendo então considerado acima de qualquer suspeita pela família e sociedade como um todo. No entendimento de Ferrari e Vecina (2002, p. 77) não há como definir um perfil único para os abusadores:

Sabemos que os que vitimizam, em geral, são os próprios pais e mães, em situação de desemprego ou não, podendo ou não fazer uso de álcool e/ou droga, com curso superior ou analfabeto, com ou sem credo determinado, rico ou pobre. Impossível criar um perfil único do que vitima, pois são pessoas que mantêm convívio social como quaisquer outras.

Os crimes sexuais não acontecem ao acaso, grande parte dos agressores sexuais age de modo premeditado. Inicialmente o abusador tenta convencer a vítima de que a atividade sexual é algo especial, divertido e normal. Ele corteja, presenteia e seduz. Busca uma aproximação da criança por meio de brincadeiras, conversas, carinhos e diversos toques corporais para ir identificando suas reações (SERAFIM, et al., 2009). Essa interação é progressiva, e à medida que vai acontecendo o molestador vai incentivando um sentimento de culpa na vítima por meio da manipulação dos laços afetivos, que garante o seu silêncio e as colocam em uma falsa posição de partícipe do abuso.

Diante das manipulações por parte do agressor, de modo a garantir que seu segredo permaneça velado, mantendo o seu perfil de "bom cidadão", o agente trabalha com a inversão do papel vítima-sedutor. Por conseguinte, a criança fica dividida entre o amor e respeito que sente pelo agressor e o ódio perante a violência física e emocional exercida por este, se sentindo responsabilizada pela perpetuação dessa situação. Sem saber como agir e sem compreender a realidade que foi inserida de maneira arbitrária, a criança se adapta a essa condição. Contudo, a legislação 
entende que essa adaptação não é considerada um "consentimento", por se tratar de um sujeito ainda incapaz de entender o que essa permissão ocasionaria:

Se a criança não procurou imediatamente uma ajuda e não foi protegida, sua única opção possível é aceitar a situação e sobreviver, ao preço de uma inversão de valores morais e alterações psíquicas prejudiciais a sua personalidade (SUMMIT, 1983).

Dias (2010), a primeira mulher a ingressar na carreira de Magistratura no Estado do Rio Grande do Sul e Vice-Presidente Nacional do Instituto Brasileiro de Direito de Família, expõe que as crianças que não foram orientadas desde o princípio, seja pela família, seja pela Escola, não possuem a capacidade de distinguir um carinho de um parente de um ato intencional de ordem sexual, assim, quando a vítima se dá conta de que se trata de uma prática erótica, simplesmente o crime já se consumou. Assim, a correspondência afetiva e até o prazer de ordem sexual não podem ser conferidos à vítima, que a isso foi conduzida de forma imprópria e injusta.

\section{A INTEGRAÇÃO DO ESTADO, FAMÍLIA E SOCIEDADE NO COMBATE AO ABUSO SEXUAL INFANTIL}

Em razão da natureza multifacetada do abuso sexual infantil intrafamiliar, é necessário a organização de ações e serviços eficazes que requer a integração e preparação das instâncias públicas governamentais e interfederativas de áreas como a educação, a segurança pública, a saúde, a assistência social, além da sociedade civil, responsável também pela proteção e garantia dos direitos das crianças. Essa integração abrange a identificação da suspeita, o acolhimento, a notificação, o encaminhamento da vítima para a Rede de Proteção e Serviços, que é onde receberá assistência médica, social, psicológica e jurídica, para assim proceder a realização da denúncia pelo Ministério Público. Nessa perspectiva, o artigo 227 da Constituição Federal de 1988 estabelece a seguinte redação:

Art. 227. É dever da família, da sociedade e do Estado assegurar à criança, ao adolescente e ao jovem, com absoluta prioridade, o direito à vida, à saúde, à alimentação, à educação, ao lazer, à profissionalização, à cultura, à dignidade, ao respeito, à liberdade e à convivência familiar e comunitária, além de colocá-los a salvo de toda forma de negligência, discriminação, exploração, violência, crueldade e opressão (BRASIL, 1988).

Necessário se faz o reconhecimento da responsabilidade solidária que a família, a sociedade e o Estado possuem em relação ao futuro das novas gerações, 
que são merecedoras de prioridade absoluta. Validando esse mesmo entendimento, o artigo 18 do ECA normatiza: "É dever de todos velar pela dignidade da criança e do adolescente, pondo-os a salvo de qualquer tratamento desumano, violento, aterrorizante, vexatório ou constrangedor" (BRASIL, 1990).

Em face da subnotificação do fenômeno do abuso sexual infantil, não há indicadores que retratem, de modo preciso, a sua incidência. A verdade no Brasil é que inúmeras crianças ainda são submetidas as mais diversas formas de violência, e para a transformação deste cenário é necessária uma mudança de posicionamento de todos os que são responsáveis pela promoção, defesa e controle dos direitos desse segmento, para que haja a criação de ambientes inclusivos em que a criança se sinta acolhida e segura para revelar a vitimização, interrompendo assim o ciclo de violência.

\subsection{Identificação dos sinais manifestos pelas crianças}

A violência doméstica contra crianças é uma questão que apresenta grande impasse na sua identificação, por se tratar de situação que acontece de modo sigiloso. Por isso, enquanto os integrados responsáveis pela defesa dos direitos das crianças não entenderem a proporção do abuso sexual, e sua preponderância no ambiente familiar, não vão sequer enxergar o que muitas vezes está a sua frente, ou seja, o professor não vai perceber o sofrimento reproduzido em um desenho, nem a mãe vai dar o interesse e valor apropriado a uma lágrima. Na percepção de Santos (2009, p. 54), algumas formas de violência praticadas contra crianças deixam marcas visíveis no corpo dessas vítimas, contudo, outras só se tornam visíveis aos olhos de pessoas que "aprendem" a ler suas evidências com o convívio atento e consciente das mudanças no comportamento da criança.

Na cultura brasileira, em que o sexo ainda constitui um tabu a ser superado, frequentemente as crianças sofrem uma repreensão por terem a "audácia" de pronunciar assuntos sexuais. Os responsáveis punem e se esquecem de questionar como tiveram a oportunidade do acesso a essas informações, colocando a culpa dessa disseminação de conteúdo apenas nos meios de comunicação midiáticos. Entretanto, aqueles que realmente aprenderam a ouvir uma criança, reconhecem a diferença significativa entre a linguagem de quem, de maneira curiosa, sente o início do despertar da sexualidade, e uma outra de quem de fato vivenciou uma situação sexual para a qual não estava preparada e consegue, por exemplo, descrever 
detalhadamente a anatomia do corpo humano ou até reproduzir com perfeição cenas de caráter sexual que não poderiam ter aprendido apenas com a observação (AZEVEDO, 2001).

A Childhood Brasil, certificada como Organização da Sociedade Civil de Interesse Público (OSCIP) e Entidade Promotora dos Direitos Humanos, com o objetivo de garantir uma infância protegida por meio do enfrentamento do abuso sexual, formulou um Guia de Referência (SANTOS, 2009, p. 57-60) para ajudar quem convive diariamente com esse público a enxergar os sinais, que se apresentados de maneira conjunta, podem revelar uma condição de violência:

1) Mudanças inexplicadas de comportamento: oscilações no humor; comportamento agressivo; perda de apetite ou excesso na alimentação; aparência descuidada e suja pela relutância em trocar de roupa; padrão de sono perturbado por pesadelos frequentes provocados pelo terror de adormecer e sofrer abuso; medo e desconfiança de contato com adultos;

2) Alteração na frequência e desempenho escolar: dificuldade de concentração e aprendizagem resultando em notas abaixo da média; queda injustificada na presença; ou ainda, quando ainda frequenta a escola, chega cedo e sai tarde, demonstrando resistência em voltar para casa;

3) Tristeza profunda: depressão crônica; comportamento autodestrutivo ou suicida; baixo nível de estima própria; autoflagelação; ansiedade generalizada;

4) Comportamentos sexuais: interesse ou conhecimento repentinos sobre questões sexuais; afeto sensualizado ou certo grau de provocação erótica inapropriada para uma criança; produção de desenhos de órgãos genitais com detalhes além de sua capacidade etária;

5) Regressão a comportamentos infantis: choro excessivo sem causa aparente; enurese (emissão involuntária de urina); perda do controle esfincteriano; chupar dedos;

6) Enfermidades psicossomáticas: são problemas de saúde sem motivo clínico aparente, como: dor de cabeça, erupções na pele, vômitos e outras dificuldades digestivas, que têm, na verdade, causa psicológica e emocional;

7) Silêncio e isolamento social: com as chantagens por meio de presentes e as ameaças de violência física e mental por parte do agressor, a criança se isola e desenvolve um sentimento de culpa, considerando-se merecedora de punições; 
8) Traumatismos físicos: os vestígios mais óbvios são questões físicas como marcas de agressão, dor, inchaço, lesão ou sangramento nas áreas da vagina ou ânus a ponto de causar até dificuldade em caminhar e sentar. Essas são as principais exteriorizações que podem ser utilizadas como provas à Justiça.

As crianças "avisam" de modos diversos, quase sempre não verbais, as situações de agressão sexual, por isso é necessário saber analisar e entender os aspectos existentes na dinâmica familiar dessas vítimas, para a detecção de famílias desequilibradas em suas relações injustas e desproporcionais de poder e submissão. Com esse conhecimento adquirido, é de extrema relevância o olhar atento das equipes de saúde, dos profissionais de ensino, da assistência social e da sociedade civil como um todo na captação, de forma humanizada, das violências "ocultas", promovendo o cuidado e o posterior encaminhamento dos casos aos entes especializados no atendimento dessas vítimas.

\subsection{Proposta de Educação Sexual nas Escolas}

A Lei de Diretrizes e Bases da Educação Nacional, Lei nº 9.394/1996 (BRASIL, 1996) estabelece que a escola é responsável pela educação integral da criança, que constitui um dever constitucional, abrangendo os processos formativos que se desenvolvem dentre outros, na vida familiar, na convivência humana, nas organizações da sociedade civil e nas manifestações culturais, complementando a ação da família e da comunidade.

O Ministério da Educação adotou, por meio dos Parâmetros Curriculares Nacionais (PCNs), uma posição de incentivar, mas não tornar compulsória, a aplicação de programas de educação sexual (ES) nas escolas. No Brasil, a temática vem sendo tratada de forma transversal, ou seja, é sugerido que o assunto seja abordado dentro de outras disciplinas. Apesar desse avanço na direção de maior promoção da ES, são recorrentes projetos de lei pela proibição do assunto no ambiente escolar. O projeto "Programa Escola sem Partido" é a referência mais propagada, que defende que questões relacionadas à educação religiosa, moral e sexual não devem ser desenvolvidas no ambiente escolar, por ser uma obrigação exclusiva da família (MORAES, 2019). 
A verdade é que existe um grande número de crianças que não têm em casa um canal de comunicação sobre sexualidade. O silêncio também educa, o fato dos responsáveis não tocarem nesses assuntos reflete uma ideia negativa de que falar sobre isso é vergonhoso, de que não se pode perguntar, e, portanto, trata-se de um assunto sigiloso. Esta concepção acaba permitindo, mesmo indiretamente, uma maior vulnerabilidade da criança, visto que uma grande vantagem utilizada pelo abusador é a apropriação desse tabu sobre a ausência de orientação sexual dentro de casa, que usa como manobra para coagir a criança a guardar o segredo com o pretexto de que "isso não é coisa que se fale para os outros", se aproveitando da condição de inocência da criança em não ter clareza de uma situação de risco e não saber se defender em circunstâncias como essa.

Quando há uma família doente, desequilibrada, que além de não orientar, acaba cometendo violência contra a própria criança, a pergunta que deve ser feita é: "como essas crianças vão se informar?". Nestes casos, o papel de educar fica subordinado à escola, que com a capacitação de seus funcionários na identificação dos sinais manifestos pelas vítimas de abuso, possui o dever de comunicação e encaminhamento dos casos aos órgãos competentes, conforme normatiza o artigo 245 do ECA. Por isso, dizer que cabe somente às famílias, e não às escolas, o papel de ensinar a criança sobre sexualidade, retrata uma falta de empatia e altruísmo. É simples julgar quando isso não pertence a própria realidade, há pais que ensinam, outros não, é necessário pensar em toda coletividade.

O importante é desmitificar a ideia de que falar de sexualidade é ensinar as crianças a terem relação sexual ou que as erotizam antes do tempo. O conhecimento é poder, é proteção, não é risco. Risco é não saber. Quando elas não sabem, quando não conhecem seus corpos, vão para a Internet, e é aí que se encontra o perigo. $O$ fato é que se não houver a soma de esforços entre família e a escola, a criança irá aprender em outro lugar, e na maioria das vezes de forma errada e distorcida. Saber sobre sexualidade, não incentiva ninguém a fazer sexo, pois é na cabeça dos adultos que esse assunto é feio, é sujo e vergonhoso, essa é a cultura que nos foi passada. Mas a criança não tem essa mentalidade, e se desde pequena houver um diálogo com naturalidade sobre isso, ela constituirá uma imagem positiva e responsável do sexo, aumentando sua bagagem para poder tomar decisões mais assertivas para a sua vida. 
A Organização das Nações Unidas para Educação, Ciência e Cultura (UNESCO) realizou uma série de estudos ao redor do mundo, em 2008 e em 2016, sobre os impactos da orientação sexual no ambiente escolar. A partir dos resultados destes estudos, verificou-se que a educação sexual contribui de forma notória para promoção do direito à saúde, à educação, à informação e não discriminação (UNESCO, 2019, p. 30). Por essa razão, a ONU se posiciona a favor da implementação de um currículo para a ES nas escolas, e tem como sua definição (UNESCO, 2019, p.16):

A Educação Integral em Sexualidade é um processo de ensino e aprendizagem com base em um currículo sobre os aspectos cognitivos, emocionais, físicos e sociais da sexualidade. Tem por objetivo transmitir conhecimentos, habilidades, atitudes e valores a crianças, adolescentes e jovens de forma a fornecer-Ihes autonomia para: garantir a própria saúde, bem-estar e dignidade; desenvolver relacionamentos sociais e sexuais de respeito; considerar como suas escolhas afetam o bem-estar próprio e o de outras pessoas; entender e garantir a proteção de seus direitos ao longo de toda a vida.

Uma vertente que dificulta a implementação da ES no ambiente escolar é a interpretação conservadora sobre a "ideologia de gênero" que carrega um sentido distorcido e pejorativo ao incitar que com a sua implementação haveria a destruição de crenças familiares e religiosas, e ainda induziria as crianças a serem homossexuais e transexuais. Porém, essa visão difere muito do que a ONU propõe como debate de gênero, que tem o objetivo de ensinar o convívio com as diferenças que naturalmente existem na sociedade, além de buscar uma igualdade de condições entre homens e mulheres, que vai muito além de conceitos sexuais e reprodutivos, tratando de questões como mercado de trabalho e nível salarial. Trabalhar gênero nas escolas é disseminar valores como igualdade e dignidade humana, é combater o sexismo, pois a evolução da sociedade exige isso. O papel é de orientar, fazer refletir, e não de impor, de doutrinar.

A proposta em questão é de que haja a inserção da ES como disciplina apartada e obrigatória em todas as redes de ensino público e privado no Brasil, desde o Ensino Infantil até o Ensino Fundamental II (como já é uma realidade em vários países como Holanda, Bélgica, Nova Zelândia, Inglaterra e Escócia), com a qualificação do corpo docente no modo de conduzir a orientação de maneira apropriada a cada faixa etária, como por exemplo a seleção de atividades (filmes, teatros, documentários, dinâmicas e oficinas) que estimulem o debate a fim de sanar 
as dúvidas e medos, desconstruindo tabus, e o respeito ao corpo, com o ensino de que as partes íntimas são assim chamadas porque devem ser cuidadas e só quem pode tocar, com a sua autorização, são os responsáveis na hora do banho ou na troca de vestimentas (SANTOS, 2009).

O Guia de Referência formulado pela Childhood Brasil é completo e muito bem estruturado para a prevenção da violência sexual, sendo assim, pode e deve ser utilizado como auxílio na qualificação dos profissionais da educação, para que promovam um trabalho educativo, de valorização humana, por meio de uma intervenção pedagógica adequada, que poderá auxiliar na consciência da criança em saber a diferença entre um carinho e um ato com intuito maldoso e inapropriado, criando um ambiente acolhedor para que essa vítima possa se sentir incentivada e segura na revelação de sua experiência, possibilitando a eliminação do sentimento de culpa oriundo da coerção exercida pelo abusador sexual.

Uma educação sexual bem orientada, respeitando o desenvolvimento psicossexual inerente a cada fase da infância, é uma das formas mais eficientes para atenuar essa condição de suscetibilidade diante do abuso sexual. Quando desenvolvida com capacitação de qualidade e material adequado a cada faixa etária, a ES é extremamente protetiva. Não se limita apenas ao tratamento de questões biológicas e reprodutoras, mas aos conceitos de autoproteção, consentimento, saúde, integridade corporal, sentimentos, emoções, responsabilidade e espécies de toques que os outros têm ou não permissão em relação ao corpo da criança, como forma de combate ao crime (ARCARI, 2018).

\subsection{Credibilidade na palavra da criança e a denúncia na esfera jurídica}

O início do caminho para que o abuso sexual infantil ingresse no sistema de justiça começa com a sua revelação pelas crianças, que depois de orientadas e acolhidas em um ambiente de confiança e segurança podem dar esse primeiro passo. Contudo, saber em quem confiar após terem suas infâncias roubadas dentro do próprio lar, por quem mais esperava receber proteção e amor, constitui uma grande dificuldade para essas vítimas.

Uma enorme decepção por parte de muitas crianças abusadas ocorre quando decidem quebrar o "pacto do silêncio" e não recebem credibilidade aos seus discursos 
pelos ouvintes, que acreditam estarem fantasiando determinada situação. O que as crianças almejam, ainda que não manifestem de modo verbal, é que acreditem nelas, nos seus sentimentos, vivências e inseguranças. É necessário que o ouvinte, seja alguém da família; da área da educação; da saúde ou da segurança, demonstre empatia e confiança em sua inocência, esclarecendo que apesar de estar triste pelas circunstâncias, sente-se orgulhoso pela coragem do relato e fará o melhor para lhe defender e dar apoio nesse momento tão delicado.

Realizada a revelação, o próximo passo é a notificação, isto é, o comunicado formal da ocorrência do abuso sexual ao Conselho Tutelar consoante normativa do ECA, que em seu artigo 13 dispõe que os casos de suspeita ou confirmação de tratamento cruel ou degradante e de maus-tratos contra criança possuem caráter compulsório na comunicação ao Conselho Tutelar de cada localidade (BRASIL, 1990). Outros canais de apoio, proteção e defesa dos direitos das crianças que recebem a notificação e realizam os procedimentos necessários para um atendimento humanizado e especializado são: Disque Direitos Humanos - Disque 100; Proteja Brasil (aplicativo gratuito); Ministério Público - Disque 127; Polícia Militar - Disque 190; Policia Civil e Delegacia Especializada de Proteção à Criança e ao Adolescente (DEPCA) - Disque 197.

Após este procedimento, inicia a fase de investigação seguindo o artigo $4^{\circ} \mathrm{e}$ seguintes do Código de Processo Penal (CPP), se forem encontrados indícios suficientes de autoria e materialidade do delito, o Ministério Público propõe a denúncia (artigo 41 do CPP), que deve ser encaminhada a um Juiz de Direito, requerendo a proteção da vítima por meio da sanção criminal do abusador (DOBKE; SANTOS; DELL'AGLIO, 2010, p.169). Nasce, então, com o recebimento da denúncia, o processo penal, que é o caminho essencial para a possibilidade de uma responsabilização penal do agressor, que nas palavras de Morgan e Zedner (2003, p. 115):

[...] primeiro, valida a experiência, deixando claro que o comportamento do ofensor é inaceitável; segundo, uma persecução exitosa pode ajudar a criança a superar a culpa de que normalmente sofre como resultado do ato pelo qual não é responsável e nos quais foi apenas envolvida por causa de sua vulnerabilidade. Finalmente, pode ajudar a quebrar o ciclo de abuso. Um dos mais importantes fatores para a restauração da saúde mental da criança abusada é de compelir o abusador a assumir responsabilidade pelo que foi feito. Isto apenas pode ser feito se for publicamente reforçada a verdade da palavra da criança, enfatizando que a criança em sentido algum deve ser vista como culpada e veemente se colocar o peso da culpa no ofensor. 
A não realização da notificação, com a consequente denúncia, significa um fator de risco para a revitimização da criança, bem como corrobora para a impunidade dos agentes. Além disso, essa atitude de quem quer que seja o ouvinte, contribui para a crença da criança de que é ela a responsável pela violência e não o agressor, já que este vem trabalhando essa concepção na mente da vítima desde o princípio. Nesse sentido, a sanção penal pode ter um importante papel simbólico para a vítima, pois traz a possibilidade de superação da infância negativa. Diante disso, havendo alguém sancionado, a criança estará isenta de culpa e se identificará no papel único e devido de vítima, resultado do reconhecimento dessa condição pelo próprio sistema judicial (ROCHA, 2017).

O ato de denúncia pode contribuir para evitar a perpetuação do abuso e fazer com que crianças vitimizadas não se tornem adultos que irão reproduzir a violência recebida. Em muitos casos a criança abusada sexualmente gera uma interpretação distorcida de suas vivências, sustentando uma culpa que não lhe pertence, com dificuldade em formar relações afetivas sólidas e problemas com a sexualidade e a autoestima. Entretanto, com o amparo educacional, médico, jurídico e psicológico, cria a possibilidade de minimização do impacto dessa experiência traumática em seu desenvolvimento, podendo levar uma vida adulta saudável e livre de amarras (SANTOS, 2009, p. 65). Portanto, a intervenção legal tem a função de mudar a condição velada em que ocorrem esses abusos sexuais, fazendo com que a família, a sociedade e o Estado tomem medidas para o enfrentamento desse crime.

\section{CONSIDERAÇÕES FINAIS}

Os estudos revisados apontam que o abuso sexual infantil, quando acontece no ambiente familiar, apresenta uma grande dificuldade na sua identificação, visto que se trata de situação que ocorre de maneira sigilosa, contribuindo para o caráter subdimensionado dos casos. Por isso a relevância em abordar o assunto e entender o contexto em que ocorre cada caso, para que seja possível a identificação dos sinais ocultos que apenas se tornam visíveis aos olhos de quem, de maneira cuidadosa, acompanha conscientemente as mudanças no comportamento da vítima. Diante disso, no decorrer do artigo foi proposta uma série de evidências manifestas pelas crianças com o objetivo de auxiliar na suspeita, desde o início, de que algo está errado e precisa urgentemente de intervenção como modo de amenizar os danos que podem 
ser ocasionados. A criança sempre sinaliza, mesmo que não verbalmente, as situações de violência. Por isso é necessário saber interpretar esse pedido de socorro que a criança, indiretamente, protesta.

Foi possível observar que uma quantidade enorme de crianças não possui um canal de comunicação sobre sexualidade em suas casas, e que além de não serem orientadas, acabam sofrendo violência dentro do próprio lar. Nesses casos de omissão familiar, ou as crianças procuram informações na Internet, ficando suscetíveis a diversos riscos, ou o papel de ensinar fica subordinado às escolas, que de modo capacitado, podem transmitir, de maneira correta e adequada a cada faixa etária, conhecimentos e reflexões a fim de protegerem as crianças. Além de criar um ambiente acolhedor, que as vítimas não possuem em casa, para que possam se sentir encorajadas a revelarem os casos de abuso, com a segurança de que serão tomadas providências necessárias e eficazes para o rompimento dessa condição de vitimização.

A proposta de implementação da educação sexual como disciplina obrigatória nas redes de ensino público e privado do Brasil, apoiada pela UNESCO e realidade em diversos países, representa um grande avanço no combate ao abuso sexual infantil, visto que tem o papel de ensinar a valoração e respeito ao corpo, com a consciência na identificação de um verdadeiro afeto e um ato malicioso de ordem sexual, a fim de assegurar a proteção de direitos e a integridade física e psicológica da criança. Contudo, sofre grande oposição de uma parcela da população que possui outra visão de que falar sobre sexualidade nas escolas caracteriza apologia ao sexo, ou ainda que influencia a conversão da identidade sexual. Diante dessa visão popular limitada, seria necessária uma desconstrução de paradigmas para a efetivação dessa proposta.

Com o entendimento do Estado, da sociedade civil e da família em relação à proporção e frequência dos casos de violência infantil no próprio ambiente familiar, faz-se necessário a credibilidade na revelação por parte da criança, que representa o primeiro passo para que o abuso sexual ingresse no sistema de justiça. Após esse ato de libertação da vítima, foi verificado que esses entes possuem a responsabilidade de notificação desses casos aos órgãos ou canais de apoio e proteção aos direitos das crianças, e como forma de utilidade pública, estes foram citados no decorrer do artigo, em conjunto com sua forma específica de comunicação, para auxiliar nos procedimentos necessários a um atendimento especializado para essas vítimas. 
Verificou-se que o objetivo de responsabilização penal do agressor fica dependente da realização da denúncia, que reforça de modo público a palavra da vítima, retirando a culpa que a ela foi implantada de maneira injusta e desproporcional pela sua condição de vulnerabilidade. A atribuição da responsabilidade exclusivamente ao agressor favorece a restauração da saúde emocional da vítima, além de contribuir para quebra do ciclo de violência, fazendo com que receba o atendimento e cuidados necessários para a superação do trauma, que coopera para a não conversão em um adulto abusador que reproduz a violência sofrida.

A intervenção legal tem a função de transformar a condição de segredo manipulada pelo agressor em que se estabelece esse tipo de violência, fazendo com que a família, a sociedade e o Estado tomem medidas para o combate desse crime. Tratar essas situações exige um trabalho integrado, para que as ações possam ser planejadas e executadas em conjunto, como a implementação de meios propiciadores à revelação, a capacitação para o reconhecimento dos sinais manifestos, a instrução do dever de notificação para que haja o atendimento humanizado às vítimas e procedência da denúncia para a incumbência da culpabilidade ao verdadeiro responsável pela transgressão de direitos da infância, restabelecendo a criança em seu devido papel de vítima pelo sistema judicial.

\section{REFERÊNCIAS}

ARCARI, Caroline. Precisamos superar o mito de que a educação sexual pode erotizar crianças. Futura, 2018. Disponível em: https://www.futura.org.br/educacaosexual-na-infancia/. Acesso em: 07 maio 2020.

AZAMBUJA, Mariana Porto Ruwer de. Violência Doméstica: Reflexões sobre o Agir Profissional. Psicologia Ciência e Profissão, Brasília, DF, v. 25, n.1, p. 4-13, 2005.

AZAMBUJA, Maria Regina Fay. Violência Sexual intrafamiliar: É possível proteger a criança?. Porto Alegre: Livraria do Advogado, 2004.

AZEVEDO, Elaine Christovam de. Atendimento psicanalítico a crianças e adolescentes vítimas de abuso sexual. Psicologia: Ciência e

Profissão, Brasília, DF, v. 21, n. 4, p. 66-77, dez. 2001. Disponível em: http://www.scielo.br/scielo.php?script=sci_arttext\&pid=S141498932001000400008\&lng=en\&nrm=iso. Acesso em: 16 abr. 2020.

BRASIL. Constituição da República Federativa do Brasil. Brasília, DF: Senado Federal: Centro Gráfico, 1988. 
BRASIL. Lei no 8.069, de 13 de julho de 1990. Diário Oficial da União, Brasília, DF, 16 jul. 1990. Estatuto da Criança e do Adolescente.

BRASIL. Lei de diretrizes e bases da educação nacional. Brasília, DF:

Presidência da República, 1996.

BRASIL. Ministério da Saúde. Análise epidemiológica da violência sexual contra crianças e adolescentes no Brasil, 2011 a 2017. Boletim epidemiológico, v. 49, n. 27, jun. 2018. Disponível em:

https://www.saude.gov.br/images/pdf/2018/junho/25/2018-024.pdf. Acesso em: 01 maio 2020.

CORRÊA, Lindinalva Rodrigues. Abuso Sexual contra Crianças e Adolescentes: denuncie. [Cuiabá]: Ministério Público do Estado de Mato Grosso, Assembleia Legislativa do Estado de Mato Grosso, 2009. Disponível em:

https://mpmt.mp.br/transparencia/source/campanhas/1.pdf. Acesso em: 15 abr. 2020.

DIAS, Maria Berenice. Incesto: um pacto de silêncio. Belo Horizonte: IBDFAM, 2006. Disponível em:

https://www.ibdfam.org.br/artigos/223/Incesto\%3A+um+pacto+de+sil\%C3\%AAncio.

Acesso em: 15 abr. 2020.

DOBKE, Veleda Maria; SANTOS, Samara Silva dos; DELL'AGLIO, Débora Dalbosco. Abuso sexual intrafamiliar: da notificação ao depoimento no contexto processual-penal. Temas em Psicologia, v. 18, n. 1, p. 167-176, 2010.

FERRARI, Dalka Chaves Almeida; VECINA, Tereza Cristina Cruz (Org.). 0 fim do silêncio na violência familiar: teoria e prática. São Paulo: Ágora, 2002.

GUERRA, Viviane N. A. Violência de pais contra filhos: a tragédia revisitada. 7. ed. São Paulo: Cortez, 2011.

MORAES, Isabela. Educação Sexual: o que é o como funciona em outros países?. [S. I.]: Politize, 2019. Disponível em: https://www.politize.com.br/educacao-sexual-oque-e-e-como-funciona-em-outros-paises/. Acesso em: 05 mai. 2020.

MORGAN, Jane; ZEDNER, Lucia. Child victims: crime, impactand criminal justice. Oxford: Clarendon Press: 2003.

OBANDO, Mireli. Abuso sexual na infância: o combate começa em casa. Campo Grande: SEJUSP, 2020. Disponível em: http://www.sejusp.ms.gov.br/abuso-sexualna-infancia-o-combate-comeca-em-casa/. Acesso em: 20 abr. 2020.

ROCHA, Maria Isabel de Matos ."Depoimento Especial" de crianças e adolescentes vítimas de violência sexual: a experiência do Estado de Mato Grosso do Sul. 2017. Disponível em: http://www.enfam.jus.br/wpcontent/uploads/2017/04/ARTIGO-Depoimento-Especial-MARIA-ISABELROCHA.R5K.pdf. Acesso em: 01 maio 2020. 
SANTOS, Benedito Rodrigues dos. Guia de referência: construindo uma cultura de prevenção à violência sexual. São Paulo: Childhood, Instituto WCF-Brasil: Prefeitura da Cidade de São Paulo. Secretaria de Educação, 2009.

SERAFIM, A. P. et al. Perfil Psicológico e comportamental de agressores sexuais de crianças. Revista de Psiquiatria Clínica, v. 36, n. 3, p. 105-111, mar. 2009.

SILVA, Lygia Maria Pereira da. Violência doméstica contra a criança e o adolescente. Recife: EDUPE, 2002.

SUMMIT, R. C. The child sexual abuse accommodation syndrome. Child Abuse \& Neglect, v. 7, n. 2, p. 177-193, 1983. DOI: https://doi.org/10.1016/01452134(83)90070-4.

UNESCO. Orientações técnicas internacionais de educação em sexualidade: uma abordagem baseada em vivências. 2. ed. rev. Paris, 2019. 